\title{
Planning and Decision Support Tools for the Integrated Water Resources Management in Vietnam
}

\author{
Christian Jolk *, Sandra Greassidis, Sylvia Jaschinski, Harro Stolpe and Björn Zindler \\ Environmental Engineering + Ecology, Faculty of Civil and Environmental Engineering, \\ Ruhr-University of Bochum, Universitätsstr 150, 44780 Bochum, Germany; \\ E-Mails: sandra.greassidis@ rub.de (S.G.); sylvia.jaschinski@rub.de (S.J.); harro.stolpe@ rub.de (H.S.); \\ bjoern.zindler@rub.de (B.Z.) \\ * Author to whom correspondence should be addressed; E-Mail: christian.jolk@ rub.de; \\ Tel.: +49-(0) 234-32-28770; Fax: +49-(0) 234-32-14701.
}

Received: 2 August 2010; in revised form: 3 September 2010 / Accepted: 15 September 2010 / Published: 28 September 2010

\begin{abstract}
Within the German-Vietnamese joint research project "Integrated Water Resources Management Vietnam”, Planning and Decision Support Tools on a regional scale are being developed. A Water Balance Tool is utilized to calculate and assess water demands and compares these with the quantity of water resources to identify surpluses or deficits. The sensitivity of water resources and the contamination potential are combined to display water quality aspects within a Contamination Risk Tool. A resulting evaluation is carried out with a Ranking Tool. It identifies areas with high priority need for action. The Planning and Decision Support Tools are being discussed with Vietnamese institutions and authorities.
\end{abstract}

Keywords: IWRM; Vietnam; water quantity; water quality; planning; decision support; contamination risk; water balance; problem ranking

\section{Introduction}

Vietnam is a country with rich water resources. A dense river network provides an abundant supply of water. Despite this comfortable situation, Vietnam faces numerous challenges: 
- The uneven distribution of the river network, the uneven rainfall across Vietnam and the prolonged dry seasons result in water supply problems in some areas.

- Vietnam is a downstream country. Important rivers drain from bordering countries into Vietnam. The quantity and quality of the surface water depends on the water usage in the upstream countries.

- The infrastructure for water supply, wastewater management, flood protection etc. is still deficient and large investments will be required during the coming decades.

- Fast urbanization, industrialization and intensification of agriculture in Vietnam leads to a rapidly increasing water demand and to severe water pollutions. Institutions in Vietnam do not yet have the capacity to efficiently plan water resource usage and control water pollution.

Since 2007 the joint research project Integrated Water Resources Management Vietnam (IWRM Vietnam), funded by the German Federal Ministry of Education and Research (BMBF), has been developing Planning and Decision Support Tools adapted to Vietnamese conditions. The IWRM project is part of the beginning implementation process of IWRM principles in Vietnam as defined by the Global Water Partnership [1]. According to the GWP the main IWRM principles are:

- Water is finite and a vulnerable resource

- IWRM is a participatory approach

- Recognizing women in their central role for the provision, management and safeguarding of water

- Realizing the social and economic value of water

- Integrating economic efficiency in water use, equity, environmental and ecological sustainability

The main goal of the research project IWRM-Vietnam is the development of Planning and Decision Support Tools for sustainable water management. The integrated approach facilitates a consideration of water resources quantity and quality leading to identification of Water Management Units (WMUs) with priority need for action.

The Institute of Environmental Engineering and Ecology $(e E+E)$ at the University of Bochum (RUB) and the Department of Water Resources Management (DWRM), of the Vietnamese Ministry of Natural Resources and Environment (MoNRE), cooperate closely to develop a method for use in compliance with Vietnamese conditions (data availability, administration and legislation).

The application of the Planning and Decision Support Tools allows for the improvement of water resources management along the principles of IWRM, which will be crucial for further socio-economic and environmental development on a sustainable basis in Vietnam.

\section{Methods and Results}

\subsection{Research Areas}

The research focuses on the development and application of Planning and Decision Support Tools to improve the IWRM in three different regions of Vietnam: the upper Dong Nai river basin (Province Lam Dong), the Red River sub basin (Province Nam Dinh) and the Mekong sub basin (City Can Tho; 
see Figure 1). These provinces are located in very different natural and geographical settings and represent the diversity of Vietnamese nature, people and economy.

The province of Lam Dong is located in the southern part of the central highlands. Dalat, the provincial capital has 190,000 inhabitants and is located 1,500 m above sea level in the northeast of the province. Lam Dong is characterized by several high plateaus with fertile soils. Main cultivation products besides coffee and tea are cashew nuts, mulberries, flowers, vegetables and fruit. Altogether a surface of 279,000 ha is under cultivation. A large proportion of the province is covered by forest.

Nam Dinh is a coastal province in the southern Red River delta in the northeast of Vietnam. It covers an area of $1,700 \mathrm{~km}^{2}$. The topography of Nam Dinh province is characterized by lowland features. It lowers gradually from northwest to southeast. The province can be divided into two regions: the polder area of the low delta plain (the lowest point is $3 \mathrm{~m}$ below sea level), and the coastal plains outside the sea dyke. There are a few hills in the northwestern part of the province (the highest is Goi at $122 \mathrm{~m}$ elevation). The coastline has a length of $72 \mathrm{~km}$, but it is extensively separated by large river mouths. The main agricultural product is rice. Furthermore there are more than 100 trade villages - many of them specialized in handicraft production — in Nam Dinh.

Can Tho City is the center of the Mekong Delta. The city is located $135 \mathrm{~km}$ southwest of Ho Chi Minh City. The total area of Can Tho is $1,401 \mathrm{~km}^{2}$ and is divided into four urban districts and four mainly rural districts. Can Tho is situated on the Hau River, which is a southeastern distributary of the Mekong River. The Mekong Delta is dominated by agricultural land use. About $50 \%$ of the national rice production is generated in the Mekong Delta. About $84 \%$ of the area in Can Tho is used for agriculture, more than $90 \%$ of it for rice production. Besides this, plant production, aquaculture and animal husbandry have become more and more important.

Figure 1. Overview of the research area.

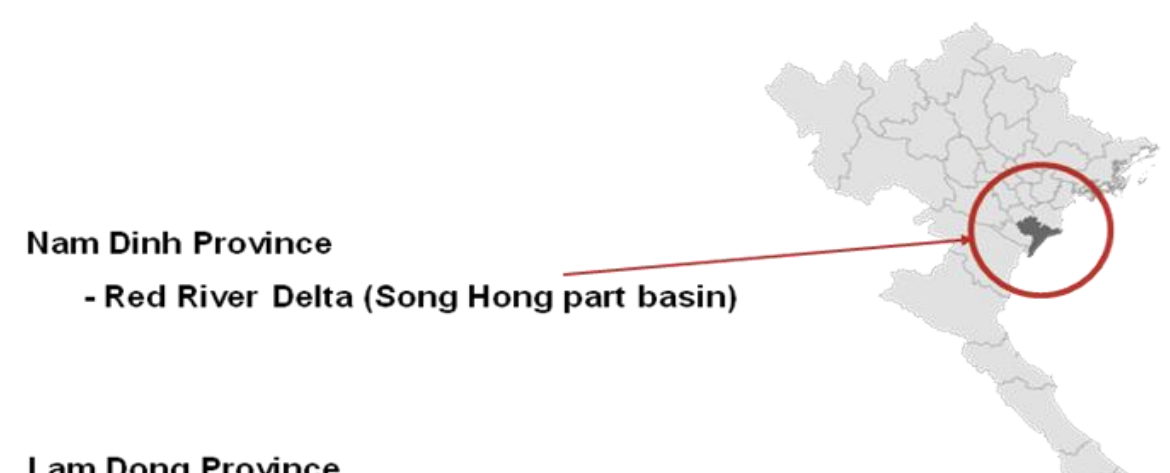

Lam Dong Province

- Southern Highlands (Dong Nai part basin)

Can Tho City

- Mekong Delta (Cuu Long part basin)

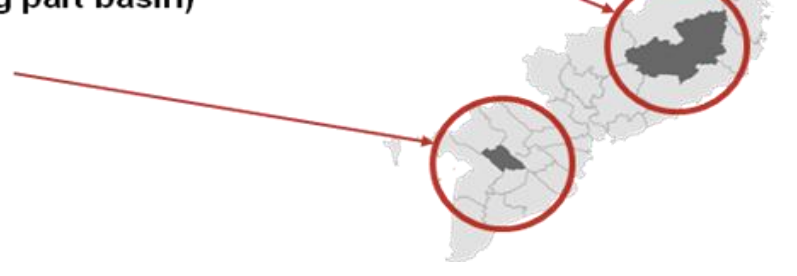




\subsection{Concept of the Project}

The research project IWRM-Vietnam develops Planning and Decision Support Tools for IWRM especially for Vietnamese conditions. It is based on the following planning levels (Figure 2). The project is carried out on the planning level of river basins.

(1) International level (international guidelines: e.g. Global Water Partnership, Agenda 21)

(2) National planning level (national Vietnamese water and environmental policy, national Vietnamese legislation)

(3) River basin planning level

(4) River sub basin planning level (WMUs)

(5) Local sites planning level (local measures)

Figure 2. Planning levels of the research project IWRM-Vietnam.

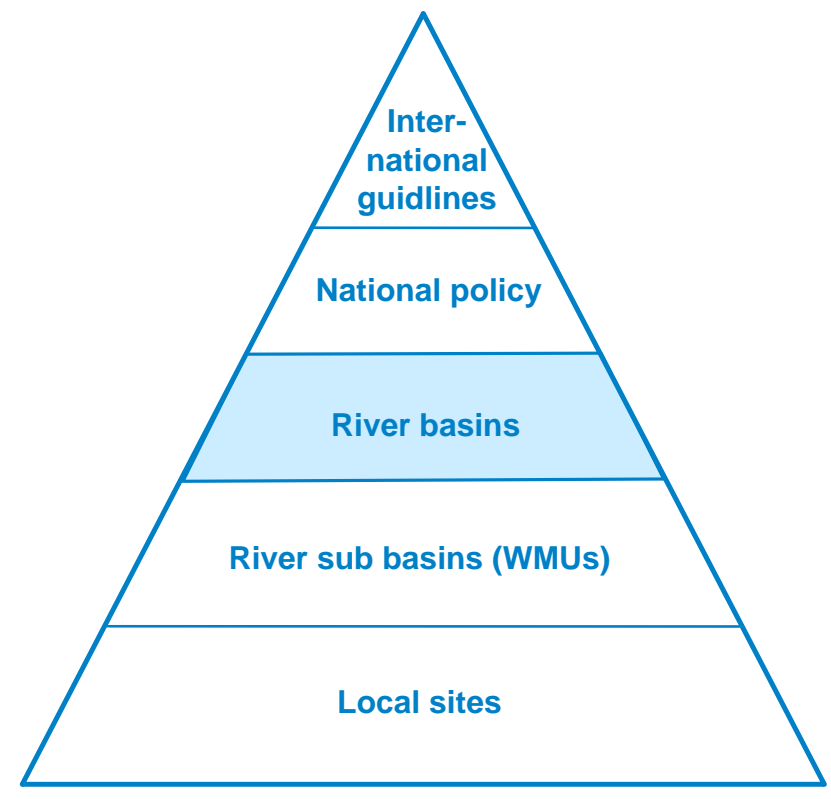

On the river basin planning level (project level of IWRM-Vietnam) the decision relevant information for identification of WMUs (Water Management Units) with priority need for action was recorded. WMUs are sub basins of a river basin that are defined for the purpose of IWRM in the river basin.

The methodical concept consists of three main tools (Figure 3):

- Water Balance Tool: Evaluation of water demand versus water resources;

- Contamination Risk Tool: Evaluation of sensitivity of water resources versus contamination potential;

- Ranking Tool: Assessment of WMUs with priority need for action. 
Figure 3. Framework for the Planning and Decision Support tools.

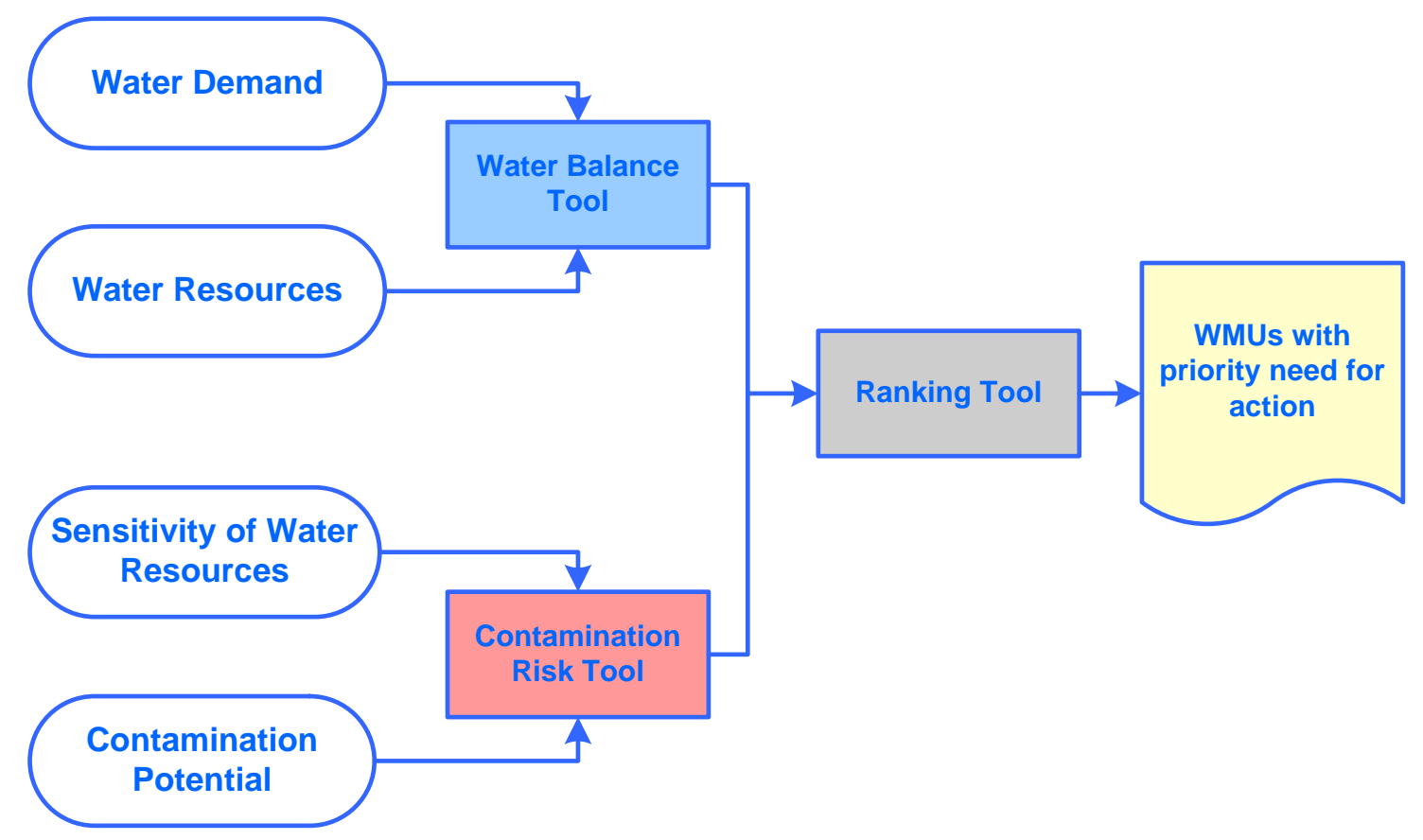

The Planning and Decision Support Tools are a dynamic approach for the analysis of diverse input data. Due to restricted data availability, the current state of the water demand calculation covers the year 2005 and the water resource is calculated for a year with average rainfall (2002). Due to general data availability and quality in Vietnam being poor, missing water-related issues (e.g., flood modeling, biodiversity conservation, etc.) are planned to be integrated into the methodical IWRM concept in the future by creating an additional thematic database. Only currently available data are considered within the IWRM Vietnam project.

The Planning and Decision Support Tools are applicable for different periods of consideration allowing the implementation of scenarios. Changes of the boundary conditions (e.g., population, climate, economy, land use) allow for a quick and easy derivation of new results.

The visualization of all input components and the results of the three tools take place in a Geographical Information System (GIS). Within the framework of the project, thematic maps with the following themes were developed:

- Basic maps: Water Management Units, administration, population density, land use, orohydrography, natural reserve, geology, soil;

- Water balance: hydrological system, water infrastructure, water resources, water demands, water balance;

- Contamination risk: infiltration into groundwater, diffuse pollution of surface water, direct discharge into surface water.

The following sections outline the application of the method, based on the case study upper Dong Nai river basin (province Lam Dong). Figure 4 shows the cascade of the WMUs and how they are linked to form a network. 
Figure 4. WMU cascade upper Dong Nai basin (Water Management Units: DN 1DN 17, LN 1-LN 4, TA 1).

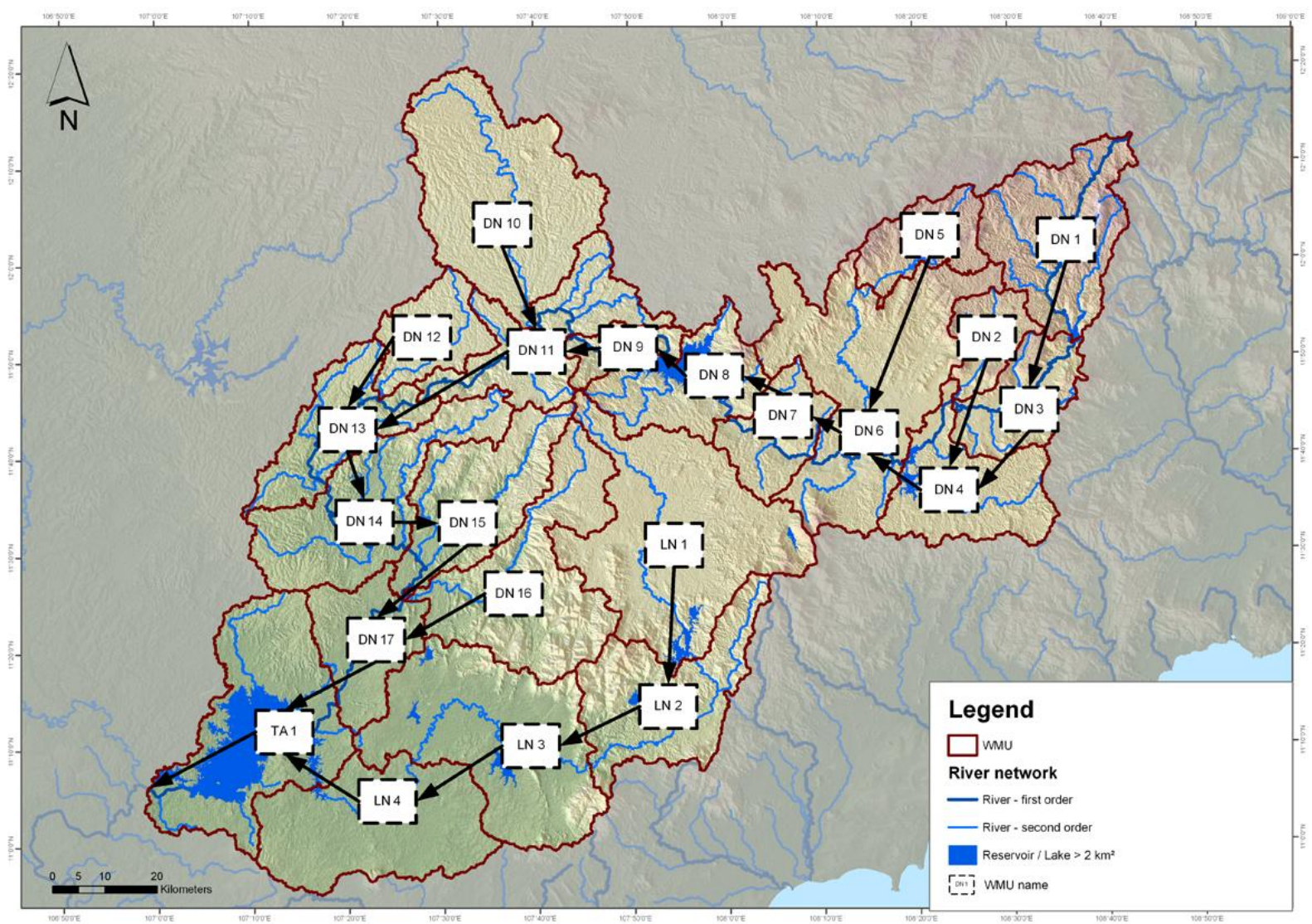

\subsection{Water Balance Tool}

The Water Balance Tool is used to calculate the water quantities of Water Management Units (WMUs) by contrasting water resources and water demands of water users, and thus identifying surpluses and deficits. The calculation is made on a monthly base, for the dry season (DecemberMarch), the rainy season (April-November) as well as for the whole year.

Figure 5 shows the components of the Water Balance Tool for water resources and water demands.

\subsubsection{Water Resources}

Parameters which define the calculation of water resources within a WMU are the discharge, yield of reservoirs, groundwater resource, and water transfers.

Input values for the discharge of a WMU are generated by employing SWAT (Soil and Water Assessment Tool, public domain supported by the USDA Agricultural Research Service at the Grassland, Soil and Water Research Laboratory in Temple, Texas, U.S.) [2].

Figure 6 shows the amount of water resource for each WMU. The red lines symbolize the WMU borders; the green segment of the pie chart represents the amount of water resources for the rainy season (unit: million $\mathrm{m}^{3}$ ); the red part of the pie chart represents the amount of water resources for the dry season (unit: million $\mathrm{m}^{3}$ ). 
Figure 5. Components of the Water Balance Tool.

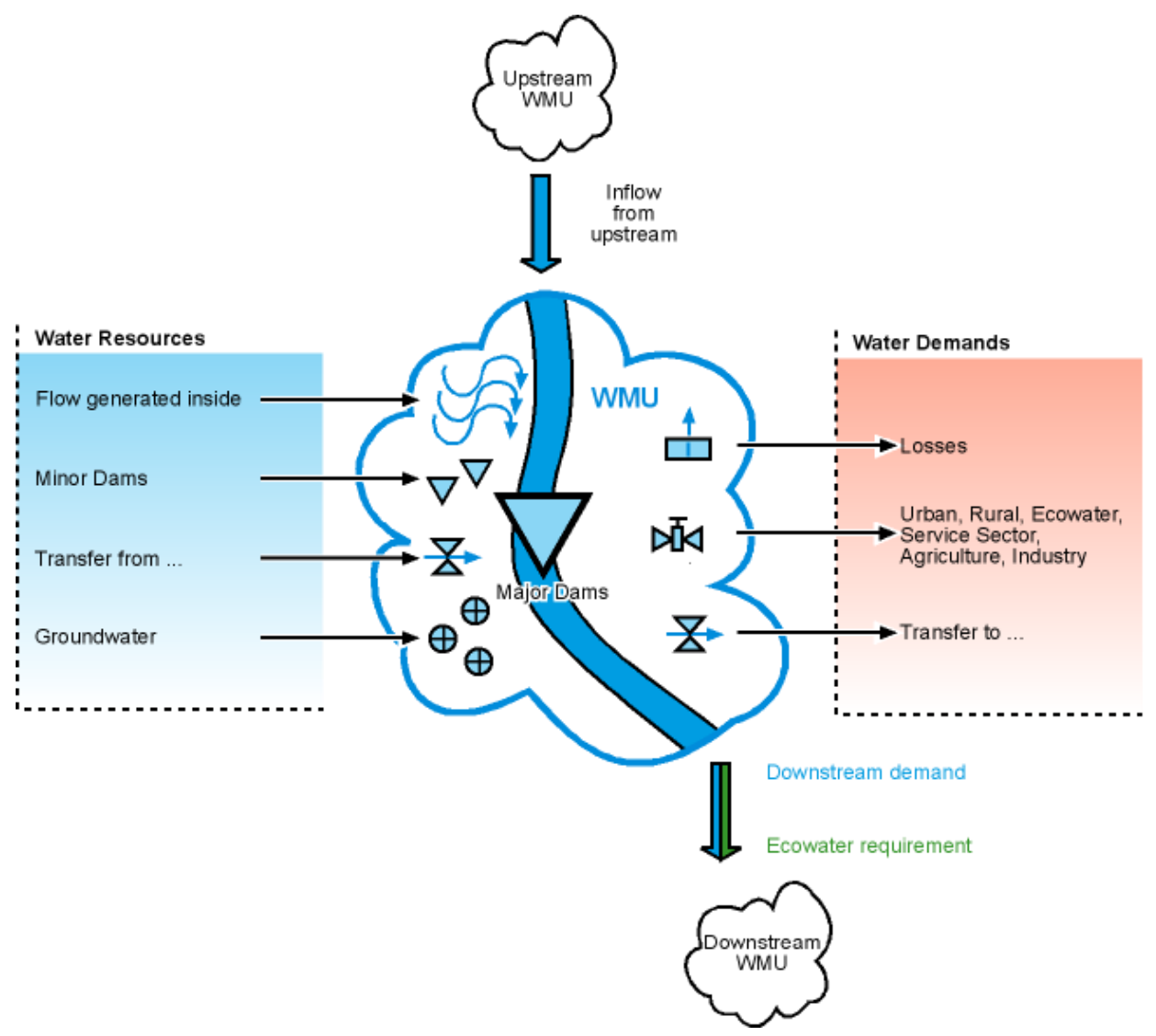

Figure 6. Amount of water resource in the WMUs.

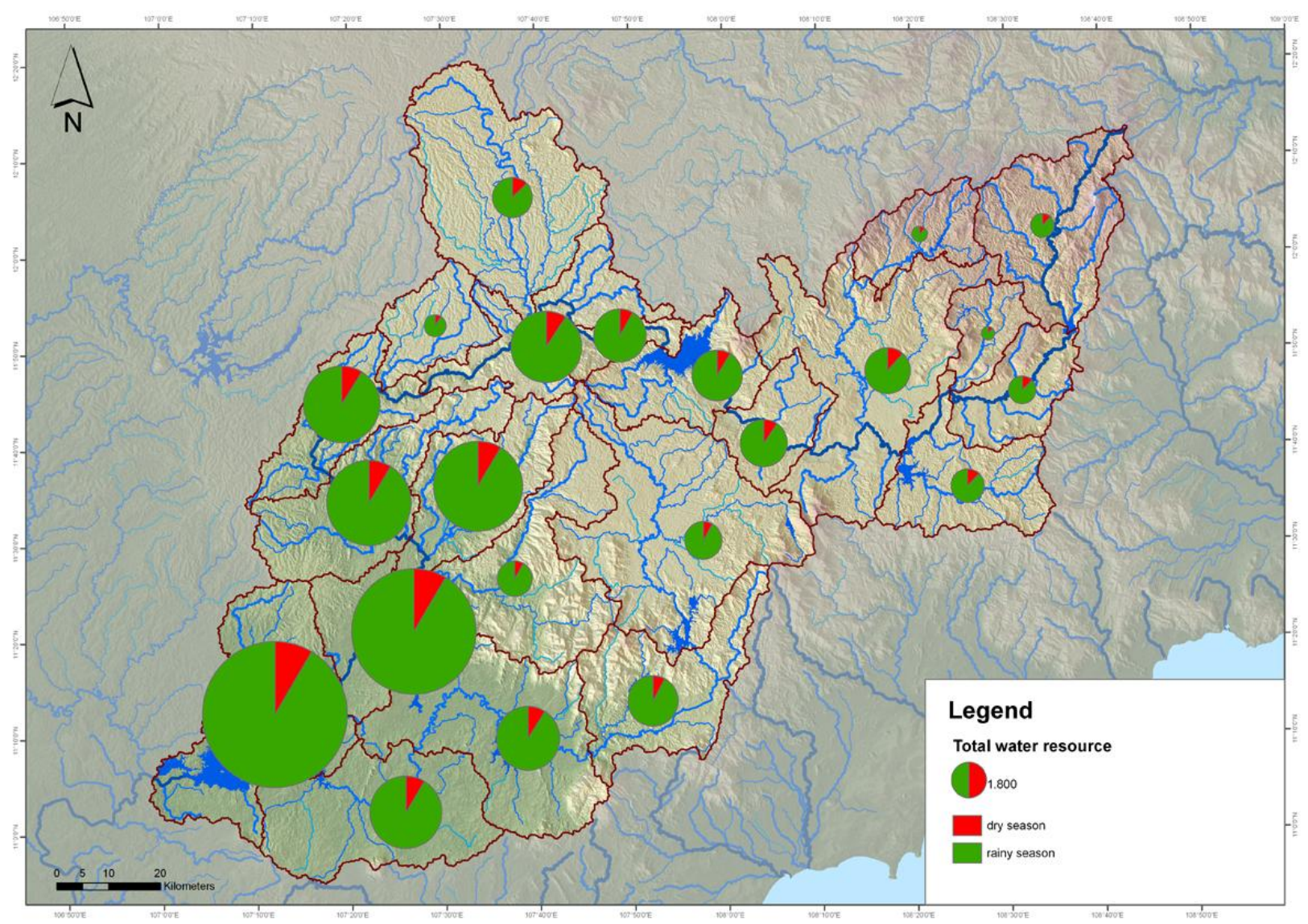




\subsubsection{Water Demand}

The water demand within a WMU consists of the following five sectors:

- Population;

- Agriculture;

- Industry;

- $\quad$ Service sector;

- Ecowater requirement.

The calculation of the water demand for the population (rural and urban population) in the model is carried out on the basis of statistical data (number of inhabitants [3]) and the defined per capita water supply targets. In addition to this, connection rates of the population as well as loss rates are considered.

The water demand of agriculture consists of irrigation demand of crops, livestock water demand and aquaculture water demand.

The calculation of irrigation demands is carried out according to the FAO method [4]. Significant input variables are the areas under specific crops (statistical data) and climate parameters, such as the effective precipitation and evapotranspiration. Furthermore, the proportion of irrigated area and losses in the irrigation system are included.

The water demand for selected categories of animals (buffalo, pigs, cattle and poultry) is determined using statistical data and supply values from literature [5].

The water demand for the aquaculture is calculated on the basis of documented aquaculture areas as well as their management manner (exchange rate fresh water, water loss, depth of basins).

The water demand for the industry is calculated on the basis of sectoral water use coefficients for specific products (literature values) and production amounts (statistical data).

The calculation of water demand for tourism in the various WMUs is based on overnight stays for national and international tourists collected in the statistical yearbook.

A first approach to assess the ecowater requirement is the Q95 flow duration index. Using average daily discharge data, flow duration curves are cumulative frequency distributions that show the percentage of time that a specified discharge is equaled or exceeded during a period of interest. The exceedance percentile Q95 can be interpreted as the flow discharge which can be expected to be exceeded at $95 \%$ of the time.

Figure 7 illustrates the dry season water demand for the different sectors (population: orange; agriculture: green; industry: purple; tourism: blue). The table depicts the total amount of water demand (unit: million $\mathrm{m}^{3}$ ). 
Figure 7. Amount of water demand for the different sectors during dry season (excluding ecowater requirement).

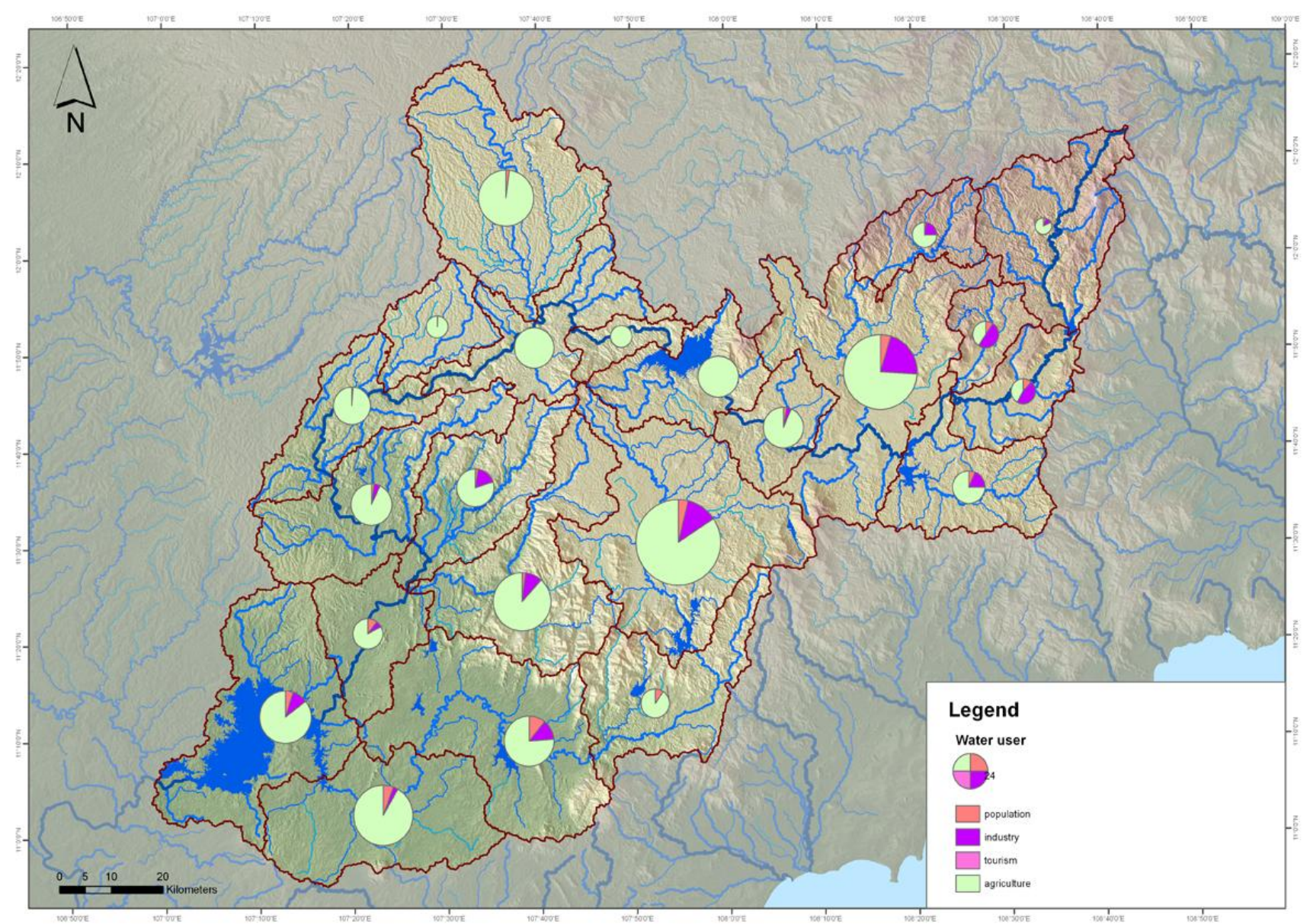

\subsection{Contamination Risk Tool}

The Contamination Risk Tool is based on the estimation of contamination risks for water resources (groundwater and surface water) as follows:

\section{sensitivity of water resources + contamination potential of pollutants = contamination risk}

To analyze the contamination potential on a regional scale, the emitters of pollutants are considered. A detailed observation of specific pollutants cannot be accomplished due to fragmentary databases. Pollutants can affect water resources via three possible contamination paths (Figure 8):

1. Infiltration of solute pollutants from diffuse and point sources into groundwater

2. Transport of pollutants from diffuse sources by erosive runoff into surface water

3. Direct discharge of pollutants from point sources into surface water 
Figure 8. Contamination paths (path 1: infiltration, path 2: erosive runoff, path 3: direct discharge).
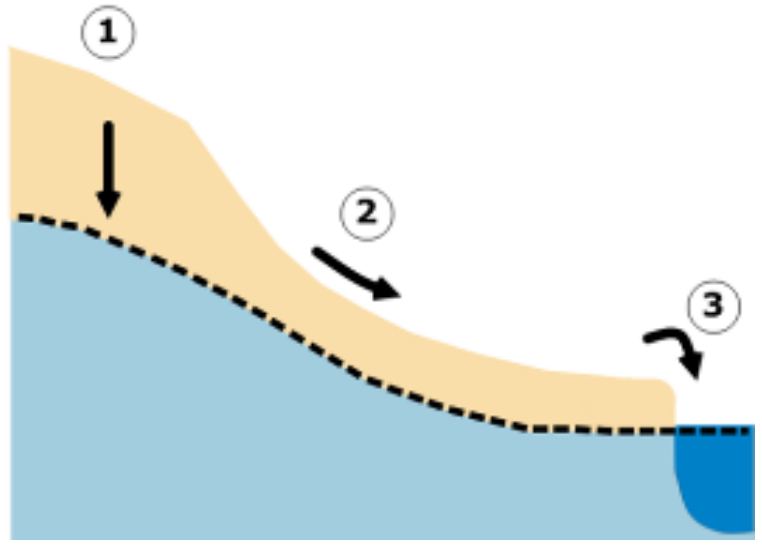

Figure 9 shows the interrelation between sensitivity of water resources, the possible causes of contamination potentials, and the resulting contamination risks for all three contamination paths. In view of the large number of thematic maps per research area (i.e., 15) created within the Contamination Risk Tool, only examples for the Dong Nai river basin are presented within this article. The example shows the method of assessing the groundwater sensitivity, the contamination potential and the contamination risk of settlements.

Figure 9. Aggregation of sensitivity of water resources and contamination potential to contamination risk.

Path 1: Infiltration

\begin{tabular}{|l|l|l|}
\multicolumn{1}{|l}{ Sensitivity } & \multicolumn{1}{l}{ + Contamination potential } & Contamination risk \\
\hline \multirow{3}{*}{$\begin{array}{l}\text { Groundwater } \\
\text { sensitivity }\end{array}$} & Contamination potential of agriculture & $\begin{array}{l}\text { Contamination risk of agriculture for } \\
\text { groundwater }\end{array}$ \\
\cline { 2 - 3 } & Contamination potential of settlements & $\begin{array}{l}\text { Contamination risk of settlements for } \\
\text { groundwater }\end{array}$ \\
\cline { 2 - 3 } & Contamination potential of point sources & $\begin{array}{l}\text { Contamination risk of point sources for } \\
\text { groundwater }\end{array}$ \\
\hline
\end{tabular}

Path 2: Erosive runoff

\begin{tabular}{|l|l|l|}
\hline Sensitivity & \multicolumn{1}{l}{ + Contamination potential } & Contamination risk \\
\hline $\begin{array}{l}\text { Surface } \\
\text { water } \\
\text { sensitivity }\end{array}$ & Contamination potential of agriculture & $\begin{array}{l}\text { Contamination risk of agriculture for } \\
\text { surface water }\end{array}$ \\
\hline
\end{tabular}

Path 3: Direct discharge

\begin{tabular}{|l|l|l|}
\multicolumn{1}{|l}{ Sensitivity } & \multicolumn{1}{l}{ + Contamination potential } & Contamination risk \\
\hline $\begin{array}{l}\text { Surface } \\
\text { water } \\
\text { sensitivity }\end{array}$ & Contamination potential of settlements & $\begin{array}{l}\text { Contamination risk of agriculture for } \\
\text { surface water }\end{array}$ \\
\cline { 2 - 3 } & Contamination potential of point sources & $\begin{array}{l}\text { Contamination risk of settlements for } \\
\text { surface water }\end{array}$ \\
\hline
\end{tabular}


The following is an explanation of the method using the example of path 1 (infiltration into groundwater).

The parameters for the determination of the sensitivity of groundwater (path 1), on the river basin scale, are the result of aquifers and groundwater use. Aquifers with a high sensitivity are hard rock with a high productivity or floodplains (Figure 10: red color, essentially basalt rock). Aquifers with a medium sensitivity are hard rock with a medium productivity (Figure 10: orange color, essentially sedimentary rock) and those with a low sensitivity are hard rock with low productivity (Figure 10: green color, essentially granite rock). Regions with groundwater use and a higher relevance for water supply are set to a very high sensitivity per se (Figure 10: hatched areas).

Figure 10. Map of groundwater sensitivity and groundwater use (path 1).

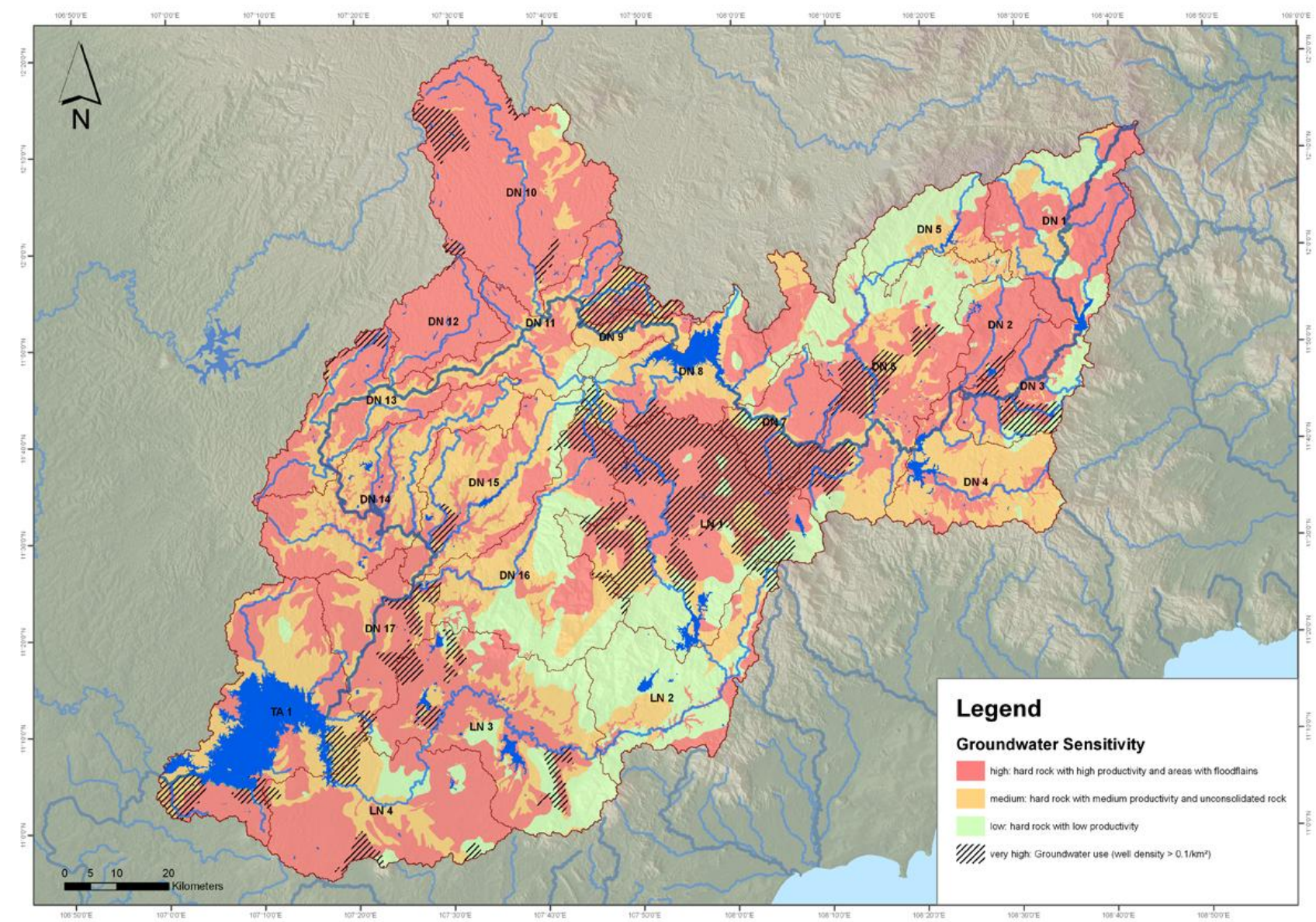

The contamination potential of settlements is relevant for path 1, because with the exception of one sewage plant in the province capital Dalat, there are no other treatment facilities. Most of the domestic wastewater reaches the groundwater. Figure 11 shows the density and distribution of settlements within the river basin. A high settlement density ( $>70$ settlement points $/ \mathrm{km}^{2}$ ) is shown in red, a medium settlements density (31-70 settlement points $/ \mathrm{km}^{2}$ ) in orange, a low settlement density (5-30 settlement points $/ \mathrm{km}^{2}$ ) in green, and no settlement contains areas with less than five settlement points $/ \mathrm{km}^{2}$. The distribution of settlements shows areas where domestic wastewater can reach the groundwater. Population data is available on district level only. Therefore, the settlement building data is used to calculate a settlement density map. 
Figure 11. Map of contamination potential of settlements (path 1).

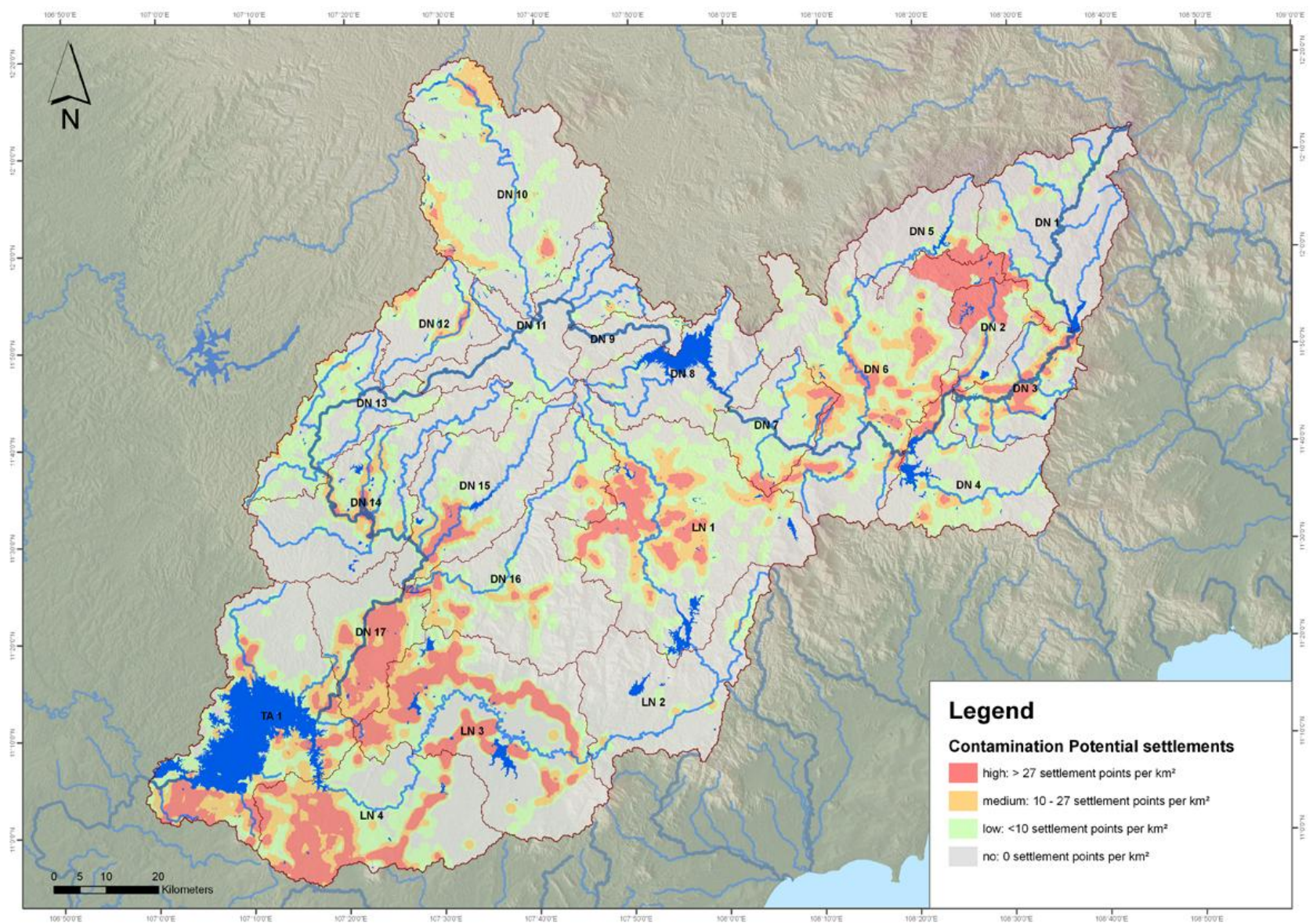

The aggregation of groundwater sensitivity, and the contamination potential of settlements to contamination risk, is carried out using the aggregation matrix shown in Figure 12. Its aim is to classify the contamination risk into three general classes (low, medium, high).

Figure 12. Aggregation of sensitivity of groundwater and the contamination potential of settlements to contamination risk.

\begin{tabular}{|c|c|c|c|c|c|}
\hline \multirow{4}{*}{$\begin{array}{c}\text { Groundwater } \\
\text { sensitivity }\end{array}$} & Very high & No & Nery high & Nery high & Nery high \\
\cline { 2 - 6 } & High & No & Medium & High & High \\
\cline { 2 - 6 } & Medium & No & Low & Medium & High \\
\cline { 2 - 6 } & Low & No & Low & Low & Medium \\
\cline { 2 - 6 } & None & No & Low & Low & Low \\
\hline \multirow{2}{*}{$\begin{array}{c}\text { Contamination risk of } \\
\text { settlements path 1 }\end{array}$} & None & Low & Medium & High \\
\cline { 2 - 6 } & \multicolumn{5}{|c|}{$\begin{array}{c}\text { Contamination potential of settlements } \\
\text { path 1 }\end{array}$} \\
\hline
\end{tabular}

The resulting map shows the different contamination risk intensities for groundwater (path 1) caused by settlements (Figure 13). 
Figure 13. Map of contamination risk settlements (path 1).

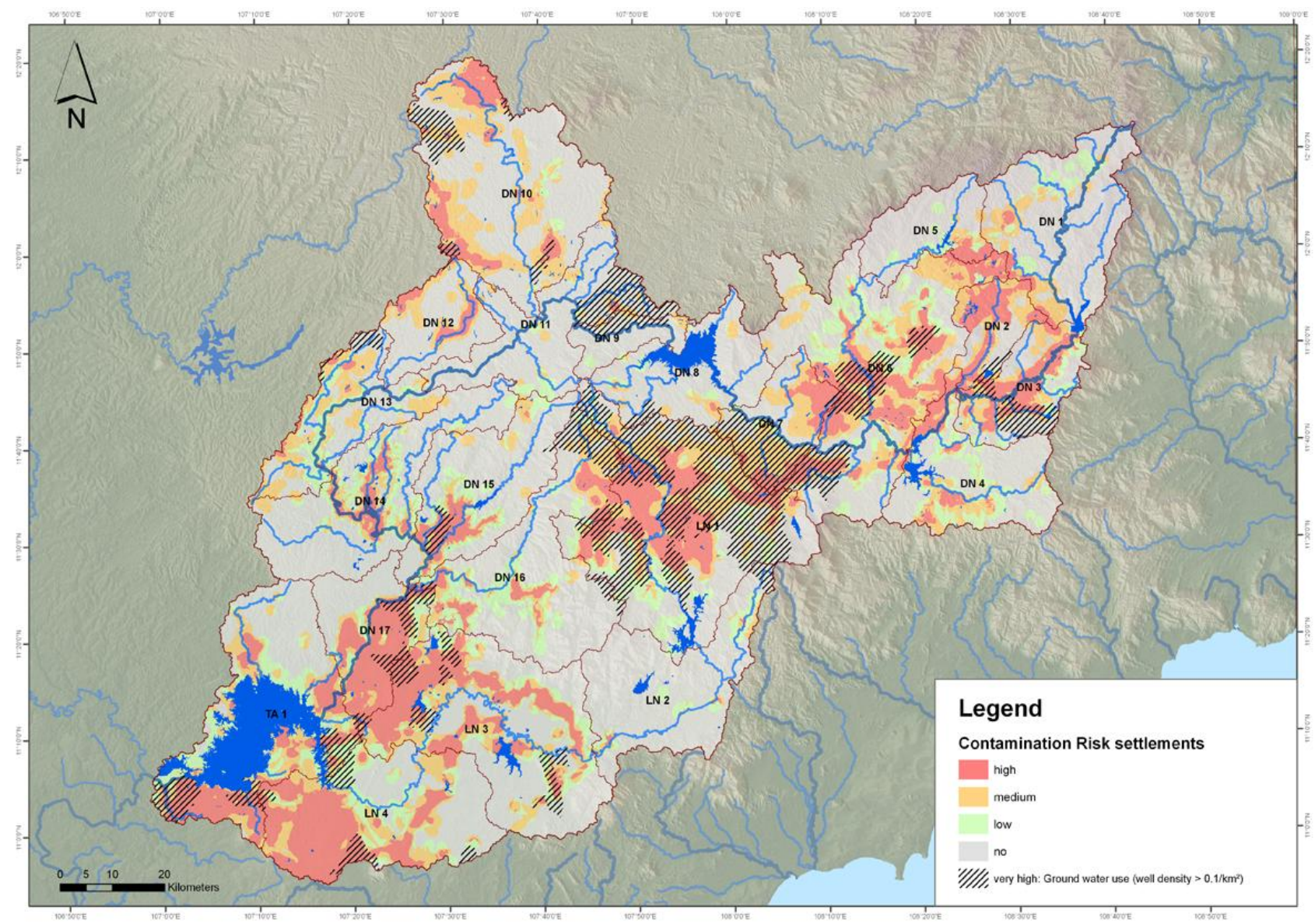

\subsection{Ranking Tool}

The Ranking Tool evaluates the results of the Water Balance Tool and the Contamination Tool in a graduated way. The ranking is visualized in tables and maps. The aim of this ranking is to identify the demand and the priorities for measures regarding water quantity and water quality in river basins in order to prepare decisions and measures.

On the basis of the Water Balance Tool for each WMU, different indicators can be calculated and ranked (possible indicators include: number of months with water deficit, water deficit per area, water availability, water exploitation index).

The results of the Contamination Risk Tool are ranked for each of the three contamination paths (see chapter 2.4.).

\section{Implementation and Changing Institutional Set-Up-Awareness Raising, Cooperation, Capacity Development}

One of the main challenges in undertaking use-oriented research projects is the sustainable implementation of the results. The prospect of implementing Planning and Decision Support Tools to be used on a large spatial and institutional scale can only be ensured by a multi-layered approach including the analysis of the institutional framework, awareness raising, and cooperation with relevant stakeholder institutions and capacity development. 
Integrated Water Resources Management and its cross-sectoral policy approach is a big challenge for governments and institutions as it generally can only be realized in a long process of implementing numerous elements, ranging from restructuring legal and institutional frameworks, investing in infrastructure and having stakeholders participate in decision making, to capacity development and establishing efficient monitoring and information systems [1]. Improving water resources management along the principles of IWRM will be crucial for Vietnam to allow further economic development on a sustainable basis. The Government of Vietnam has recently undertaken several important steps towards IWRM. It adopted the National Strategy on Water Resources towards the Year 2020 that clearly endorses IWRM principles [6]. With support of international development partners, the government also compiled a Water Sector Review to reflect on the main water related issues on a national level [7].

Planning and Decision Support Tools embedded in the context of IWRM principles require the consultation of stakeholders and close cooperation with institutions which will put the method into regular practice. $\mathrm{eE}+\mathrm{E}$ is taking a top-down/bottom-up approach in order to assure that the Planning and Decision Support Tools meet the pressing issues of the water sector and adapt these into the actual needs of Vietnamese decision makers.

The layered capacity development measure concept includes training on the basic use of the geographical information system ArcGIS by ESRI, advanced ArcGIS training on the Water Balance Tool and the Contamination Risk Tool utilizing step-by-step GIS manuals, general and tool based introductions, and discussions about methodical definitions together with in-depth discussions about the suitability of the chosen data categories and notations. Another discussion covers indicators used to operate the Problem Ranking Tool. The poor quality and availability of data has been brought up as a general issue to raise awareness within high level administration, hoping to spread the need for improvement to subordinate agencies and data collecting companies via DWRM. On this note, DWRM has been sensitized to additional data needs for the optimal performance of developed methods. Some of those needs are not exclusively beneficial to the Planning and Decision Support Tools, but are also suitable to meet the demands of other sectors. One spin-off example can be found in the development of an IWRM-register of industries (including, for example, water demand, discharge, specific pollutants, etc.).

\section{Conclusions}

The Planning and Decision Support Tools presented in this article allow for an analysis and visualization of the water management situation in the project area. The results will further be interpreted by using the Ranking Tool. This enables the user to derive measures for WMUs with priority need for action. Possible measures include e.g. monitoring concepts, construction of water sanitation and supply facilities or optimization of agricultural processes. eE $+\mathrm{E}$ and the MoNRE initiated a close cooperation to ensure a holistic implementation of the tools and a close interaction between the method and legislative framework in Vietnam. The early participation of the responsible water agency on a national level (DWRM) guarantees a sustainable adjustment and a nation-wide transferability of the method to Vietnamese conditions.

The overall concept developed by the joint research project IWRM Vietnam is an important step towards the implementation of IWRM principles in Vietnam. 


\section{Acknowledgements}

For text review and commentaries we would like to thank Nils Führer. For corrections of text and grammar we would like to thank Niko Aslanidis.

\section{References}

1. Agarwal, A.; delos Angeles, M. Integrated Water Resources Management, 1st ed.; Global Water Partnership: Stockholm, Sweden, 2000.

2. Neitsch, S.L.; Arnold, J.G.; Kiniry, J.R.; Williams, J.R.; King K.W. Soil and Water Assessment Tool. In Theoretical Documentation Version 2000; Grassland, Soil \& Water Research Laboratory, GSWRL Report 02-01, Blackland Research and Extension Center, BRC Report 02-05, Temple, Texas, USA, 2002.

3. Provincial Statistical Offices, Ed.; Statistical Yearbook Lam Dong, Dong Nai, Binh Tuan, Binh Phuoc, Dak Nong, Dalat, Dong Nai, Phan Thiet, Dong Xoai, Gia Nghia, Vietnam, 2007.

4. Richard, G.; Luis S. Crop Evapotranspiration-Guidelines for Computing Crop Water Requirements; FAO Irrigation and drainage paper 56; FAO: Rome, Italy, 1998.

5. Legel, S. Nutztiere der Tropen; In Band II und III, 1st ed.; Hirzel: Stuttgart, Germany, 1990.

6. MONRE. National Water Resources Strategy towards the Year 2020, 1st ed.; Ministry of Natural Resources and Environment: Hanoi, Vietnam, 2006.

7. Cuddihy, W.; Frederiksen, H. Viet Nam Water Resources Sector Review, 1st ed.; World Bank: Washington D.C., USA, 1996.

(C) 2010 by the authors; licensee MDPI, Basel, Switzerland. This article is an open access article distributed under the terms and conditions of the Creative Commons Attribution license (http://creativecommons.org/licenses/by/3.0/). 